\title{
Rangers can't be with every elephant: assessing rangers' perceptions of a community, problem- solving policing model for protected areas
}

\author{
William D. Moreto and Richard Charlton
}

\begin{abstract}
Recent studies have highlighted that illegal activities occurring within protected areas, including the poaching of fauna and flora, cannot be addressed with increased law enforcement alone. Moreover, research on the increasingly militarized nature of front-line conservation efforts has pointed to potentially detrimental aspects of such approaches. This has led to a shift in focus to identifying ways to further engage local communities in the prevention and reduction of wildlife crimes. However, few studies have examined the potential for changing the responsibilities of front-line conservation personnel or their views on such changes. Such insight is vital in forecasting the successful adoption of, or possible resistance towards, a more community-oriented policy. We examined rangers' perceptions in Uganda to assess their attitudes towards traditional enforcement strategies and alternative, non-enforcement approaches for reducing illegal activities in protected areas. Our findings suggest that although respondents believed that traditional enforcement strategies (e.g. foot patrols) are important and effective in reducing wildlife crime, these strategies on their own were insufficient to address illegal activities. Study participants emphasized the importance of expanding the role of front-line rangers, in line with approaches suggested in the policing literature. We discuss the implications of our findings for transdisciplinary conservation science research and front-line conservation policy and practice.
\end{abstract}

Keywords Attitudes, community-oriented policing, conservation science, problem-oriented policing, protected area management, rangers, Uganda, wildlife law enforcement

\section{Introduction}

Challender \& MacMillan (2014) argued that despite increased attention and investment in enforcement and anti-poaching efforts, poaching is ultimately more than an enforcement problem. They proposed a three-pronged approach to addressing this crime: (1) building capacity to

William D. Moreto (Corresponding author) and Richard Charlton Department of Criminal Justice, University of Central Florida, 128065 Pegasus Drive, Orlando, Florida, 32816-1600, USA

E-mail william.moreto@ucf.edu

Received 29 September 2018. Revision requested 7 November 2018.

Accepted 20 November 2018. First published online 22 July 2019. incentivize local communities, (2) re-examining market prices for wildlife products, to assess sustainable offtake mechanisms and, if necessary, utilize economic mechanisms to fund conservation, and (3) reducing demand through social marketing programmes. Although they observed that the 'mainstream adoption of this strategy would represent a radical shift from an enforcement geared approach, at an ever-increasing cost, to more community-based natural resource management' (Challender \& MacMillan, 2014), there was little discussion of how enforcement efforts can be altered to support such a shift.

Here we assess front-line rangers' attitudes towards law enforcement and anti-poaching efforts in protected areas and examine how such efforts can be transformed to complement the community-based natural resource management approach proposed by Challender \& MacMillan (2014). Specifically, we propose that exploring front-line protected area management and monitoring from a policing perspective provides valuable insight because several aspects of policing are relevant to conservation (Moreto et al., 2017). Similar to the notion that poaching is more than an enforcement problem, rangers should be viewed as more than only anti-poaching personnel or militarized enforcement agents.

Research suggests that traditional law enforcement strategies, which rely primarily on patrols, arrest and the threat of punishment, are necessary to ensure protection and management of protected areas (Moore et al., 2018). However, anti-poaching efforts should not rely on deterrence-based approaches alone, because the deterrent effect of patrol activities is limited (Barichievy et al., 2017). Studies examinating the impact of community-based conservation programmes in Uganda have shown mixed results. Blomley (2003) found that community-focused multiple-use programmes in Bwindi Impenetrable and Mgahinga Gorilla National Parks were effective in developing a collaborative management environment. This was believed not only to reduce illegal activities within the Parks, but also to decrease tensions between local communities and Park authorities. Infield \& Namara (2001), however, found that although the community conservation programme implemented in Lake Mburo National Park influenced some interactions between Park staff and communities, communities' attitudes towards conservation or the Park and its staff were not affected positively.

The potential challenges associated with anti-poaching efforts are not unique to wildlife-related law enforcement. 
Questions concerning the efficiency and effectiveness of traditional police strategies generally have received considerable attention. Research suggests that deterrence-based, reactive approaches have a limited impact on crime, disorder and citizen's fear of crime (National Research Council, 2004). This has led to the development of alternative, nonenforcement strategies that focus on fostering community co-production and problem-solving approaches.

Community-oriented policing emphasizes a decentralized model, endorsing front-line officer decision making and involvement with local citizens to help establish community involvement, trust, rapport and co-production (Gill et al., 2014). This places a greater emphasis on service provision and crime prevention rather than on crime control and order maintenance. Three key factors are necessary for community-oriented policing (Lawrence \& McCarthy, 2013): (1) organizational transformation (i.e. management policies that support community engagement), (2) community partnership (i.e. engagement with neighbourhood associations), and (3) problem solving (i.e. addressing recurring community problems).

A problem-oriented policing approach acknowledges the limitations associated with reactive policing models, which only deal with specific criminal incidents rather than with recurring problems that cause such events. This approach redefines the role of police officers by highlighting their potential as problem solvers rather than simply enforcers of the law (Goldstein, 2003). By addressing recurring problems, not only can crime be prevented, but reliance on the criminal justice system can be alleviated. Problemoriented policing seeks to include a variety of community stakeholders, such as residents, business owners and religious figures. Community involvement is crucial for two reasons: firstly, members of the local community are best situated to identify and conceptualize problems that result in criminal activity. Secondly, the community and its resources can be used to develop solutions that do not involve the criminal justice system. This is key not only in reducing the burden on the criminal justice system, but it provides police with an additional set of tools that can be employed before more formal tactics are utilized (Kennedy, 2009).

Community- and problem-oriented policing can take different forms and is influenced by various factors relating to the community in question. In the context of Uganda, one study found that the introduction of community liaison officers improved community-police relationships (Tindifa \& Kiguli, 1997), whereas other research suggests that community-oriented policing in the country lacks proper conceptualization, design and implementation of the role played by community liaison officers (Van der Spuy \& Röntsch, 2008). To our knowledge there has been no empirical study of problem-oriented policing in Uganda.

Rangers are the most visible component of the criminal justice system to communities near protected areas and can therefore be viewed as front-line representatives of conservation policy. They play a central role in the way conservation initiatives are implemented and in how these initiatives are presented to and understood by local community members (Moreto et al., 2017). The aim of this study is to understand front-line experiences and perceptions of current practice, to gauge the possibility for change and the nuances associated with the potential adoption and expansion of innovative policing approaches for conservation.

\section{Methods}

We sought to address three research objectives: (1) examine rangers' attitudes towards traditional enforcement and alternative, non-enforcement strategies to reduce illegal activities in Ugandan protected areas, (2) assess rangers' perceptions of the effectiveness and challenges of both traditional law enforcement strategies and alternative approaches to reduce illegal activities, and (3) examine rangers' views of the type of training needed to successfully perform their duties.

We collected data during June-August 2014 from three protected areas (Kibale, Lake Mburo and Queen Elizabeth National Parks), the Uganda Wildlife Authority headquarters in Kampala and the Uganda Wildlife Education Center (Entebbe; Fig. 1). Study settings were chosen for their variation in physical size and topography, location and organizational size. We used a mixed purposeful sampling approach to identify interview respondents from an administrative staff list provided by command staff at each site. Specifically, we employed utilization-focused sampling, which 'involves selecting cases that will be relevant to the issues and decisions of concern to an identifiable group of stakeholders and intended users' (Patton, 2015, p. 295), and operational construct sampling, which results in the selection of 'real-world constructs' with the intent of 'deepening or verifying theory in new contexts, new time periods, or new situations' (Patton, 2015, p. 289).

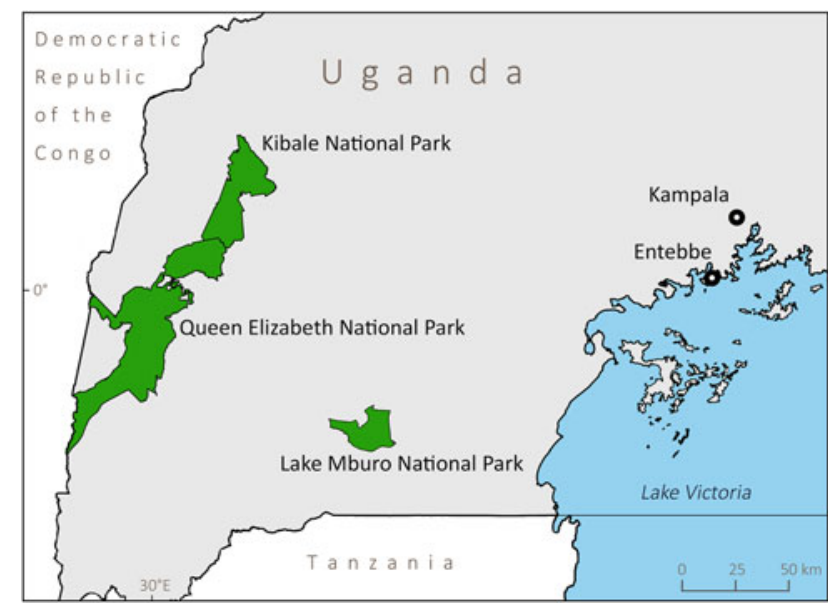

FIG. 1 Location of the five study sites in Uganda. 
We continued sampling until theoretical saturation or sufficiency (Dey, 1999) was attained as determined by preliminary coding of interviews during data collection. Specifically, WDM performed initial manual coding on field notes collected during interviews and observations and constructed narratives to articulate initial overarching themes. These codes and narratives were then used to gauge whether the presence of similar and recurring responses suggested saturation. Finally, WDM solicited additional insights from study participants on site, to ensure that the documentation and interpretation of events and opinions were accurate.

We interviewed 89 rangers, including law enforcement $(\mathrm{n}=73)$, intelligence $(\mathrm{n}=8)$ and community conservation rangers $(n=8)$. Twenty-three respondents were from Kibale National Park, 23 from Lake Mburo National Park, 29 from Queen Elizabeth National Park, 8 from the Uganda Wildlife Authority headquarters in Kampala and 6 from Uganda Wildlife Education Center (Entebbe). The response rate was $98 \%$ and our sample reflected $32 \%$ of the total ranger population at the five study sites. Most respondents $(84 \%)$ were male. All interviews were carried out face-to-face and in private. The majority of respondents $(83 \%, n=73)$ were willing to have their interviews audio recorded; all interviews were documented with detailed hand-written notes. The semi-structured interview guide comprised open-ended questions, enabling additional probing when necessary. Interviews lasted c. 1 hour. Additionally, we completed an estimated 600 hours of observation, including participant observation of ranger foot patrols and informal interaction during off-duty periods. These observations were useful in developing rapport with study participants and contextualizing interview data (Patton, 2015).

We analysed data using ATLAS.ti 7 (ATLAS.ti Scientific Software Development GmbH, Berlin, Germany). A threestep approach was used for analysis: firstly, we utilized first-order hypothesis coding or the 'application of a researcher-generated, predetermined list of codes to qualitative data specifically to assess a researcher-generated hypothesis' (Saldaña, 2016, p. 171). We identified concepts that fit within traditional, community-oriented and problem-oriented policing frameworks and categorized data that did (or did not) fit within these frameworks, including approaches that focused on arrests and patrols, fostered active engagement with community members besides traditional law enforcement duties (e.g. patrols), identification of problems that led to criminal activities within protected areas, the practice of problem-solving, active collaboration with community stakeholders, and the application and assessment of problem-specific strategies. In total, we developed 43 distinct codes to apply to the data. We then used second-order elaborative coding or 'the process of analysing textual data in order to develop theory further' (Auerbach \& Silverstein, 2003, p. 104) and refined first-order codes to support theoretical propositions associated with traditional, community-oriented and problem-oriented policing themes. Finally, we discussed the identified themes to ensure consistency. For ease of presentation, we address each research question separately and provide supporting quotations which best reflect the consensus amongst our respondents. Pseudonyms are provided for respondents to ensure confidentiality.

\section{Results}

Rangers' attitudes towards different law enforcement approaches

To understand respondents' attitudes towards traditional law enforcement strategies, it is important to note that paramilitary training is the primary education method for wildlife rangers in Uganda. Given that this kind of training focuses primarily on activities within Park boundaries, it was not surprising that law enforcement respondents considered the Park to be their 'office' (Ezra). Most respondents $(n=73)$ viewed traditional law enforcement activities such as foot patrols as the primary strategy to address illegal activities in protected areas. In addition to their role in addressing illegal activities, patrols are also an integral aspect of ranger-based data collection, which results in important ecological and environmental data necessary for the successful management of protected areas.

Beyond traditional law enforcement strategies, study participants identified three alternative, non-law enforcement approaches they believed were helpful in reducing illegal activities in protected areas: (1) providing services and allowing community access to protected areas, (2) educating the community on conservation, sharing information and interacting with community members and local leaders, and (3) establishing tangible and sustainable alternatives to poaching. Importantly, throughout these discussions, respondents highlighted the integral role that the community played in preventing and reducing illegal activities within and outside protected areas, echoing the findings reported in the policing literature (see Table 1).

\section{Providing services and protected area access}

One major source of contention between communities and Park authorities were negative interactions with wildlife, such as wild animals using crops, killing or transmitting diseases to livestock, or attacking and harming community members (Moreto, 2019). Respondents described proactive measures they could take to prevent such interactions, for example the building of trenches to keep wildlife from entering community land. Similar to findings of policing research, such direct engagement with the community helps reinforce the public service element of the ranger profession. 
TABLE 1 Respondents' $(n=89)$ perceptions towards alternative, non-enforcement conservation strategies in Uganda.

\begin{tabular}{|c|c|c|}
\hline Themes & $\begin{array}{l}\text { No. of respondents with } \\
\text { supporting statements }\end{array}$ & Supporting quotes \\
\hline $\begin{array}{l}\text { Providing community access } \\
\text { to the protected areas \& resources }\end{array}$ & 21 & $\begin{array}{l}\text { Before we sign a memorandum of understanding, communities will } \\
\text { tell them to identify some of the resources that they want to access } \\
\text { within the Park [...] So in the process of investing these resources in } \\
\text { these people, these people would keep telling us where illegal } \\
\text { activities are being seen in the areas where they are investing } \\
\text { resources, so they become part of us. (Hamilton) } \\
\text { They (management) should really consider these neighbouring } \\
\text { communities [...] The communities, [they are the ones] who has } \\
\text { been living with these wildlife. Killing their human lives, they are } \\
\text { destroying their crops, \& they have managed to stay with these } \\
\text { wildlife. And you make them to pay entrance when they have } \\
\text { decided to bring their family into the Park? It is really making me } \\
\text { unhappy. Let communities be respected [...] [Give them] free } \\
\text { [access to the Park]. (Harriett) } \\
\text { Meeting community members \& at times inviting those community } \\
\text { members to come in \& interact. To share ideas. We take them } \\
\text { around the Protected Area. They can also feel that this is a part of us } \\
\text { [...] That's when you can secure the resources we have here, because } \\
\text { if you talk to them \& they feel a part of it (conservation) [...] The } \\
\text { resources are also theirs. (Jacob) }\end{array}$ \\
\hline $\begin{array}{l}\text { Educating the community on } \\
\text { conservation, sharing information } \\
\text { \& interacting with community } \\
\text { members \& local leaders }\end{array}$ & 59 & $\begin{array}{l}\text { Most of the communities lack conservation knowledge. They don't } \\
\text { know these animals are supposed to be there for generations to } \\
\text { come. So for them they feel like if you go \& shoot a buffalo it's just } \\
\text { something where you get that meat \& you go \& eat. Then you (the } \\
\text { ranger) become an obstacle, so the relationship there is very, very, } \\
\text { very difficult. (Boaz) } \\
\text { We arrested one guy \& he wasn't a poacher. He was looking for a } \\
\text { certain way to get to one outpost to ask something. So the group of } \\
\text { rangers on patrol who got (arrested) him [because] it is still illegal to } \\
\text { be in the Park without permission [...] I felt bad for him because he } \\
\text { didn't know. So I felt he should have known [the laws] because if he } \\
\text { had known, he wouldn't have been arrested [...] More rangers } \\
\text { should be educated on community conservation. More rangers } \\
\text { should be taken there (into the communities) to teach communities. } \\
\text { (Paul) } \\
\text { When we get \& sensitize the local communities, they keep on } \\
\text { communicating. If they see that you (referring to another commu- } \\
\text { nity member) want to go back to poaching, at times they'll call us, [\& } \\
\text { say], 'You come help. This man is about to go poaching.' (Moses) } \\
\text { The (community) meetings have also involved (community) lea- } \\
\text { ders. The Local Council's at the village level, at the parish level, at the } \\
\text { subcounty level, \& even our district. So, those leaders also help } \\
\text { during the absence of the Park staff. They continue sensitizing them } \\
\text { (community members). (Patrick) }\end{array}$ \\
\hline $\begin{array}{l}\text { Providing tangible \& sustainable } \\
\text { alternatives }\end{array}$ & 9 & $\begin{array}{l}\text { Maybe employment. Employing the so-called 'notorious poachers' } \\
\text { to the Park. In a government institution, that can also reduce } \\
\text { poaching [...] When somebody has something to do, he will have } \\
\text { come out from that poverty line level. (Barnabas) }\end{array}$ \\
\hline
\end{tabular}

Another strategy employed by the Uganda Wildlife Authority were memorandums of understanding with communities. These formal agreements enable local citizens to access Park resources (e.g. firewood) during specific time periods and at certain locations. Importantly, providing such access to facilitate funerals, weddings and other community events was described as helping to foster positive community relations. Finally, respondents proposed that local community members should be given free access to enter and enjoy the protected areas. Rangers believed that this was important to establish a sense of ownership and stewardship amongst the local community. 


\section{Conservation education, information sharing and community interactions}

Interviewees were aware that although law enforcement rangers were primarily responsible for the management and monitoring of activities within Park boundaries, threats originated from outside the Park. Respondents also felt that protected area management and monitoring effectiveness was largely dependent on community perceptions of conservation. To foster positive attitudes towards conservation, the Uganda Wildlife Authority organized and participated in community sensitization meetings. These meetings were led by the Community Conservation Department and provided the Authority with a venue to highlight local conservation efforts and the activities of the organization.

These meetings were also important from a tactical perspective: most law enforcement respondents believed that traditional law enforcement strategies (e.g. foot patrols) were insufficient to reduce poaching in protected areas and considered community sensitization meetings beneficial in reducing illegal activities. Specifically, respondents viewed community meetings to be a mechanism for developing informal social control and guardianship. Rangers believed that by sensitizing community members to the benefits of protected areas, villagers would be willing to intervene in potential illegal activities or provide useful information for ongoing investigations.

Community meetings also enable rangers to educate community members about Park rules and regulations, and the Uganda Wildlife Act. Respondents explained that community members were often not familiar with the laws and regulations governing the Park, which they attributed to high levels of illiteracy, and to the advanced age of some community members. Importantly, the meetings also enabled the Uganda Wildlife Authority and nearby communities to interact and to develop rapport. Although such meetings were 'not easy' at times, they were important in 'bridging the gap between antagonistic parties' (Alice). An important outcome of these meetings is not only a reduction of illegal activities, but an improvement in community-ranger relations, with community members developing trust in the rangers and perceiving them as legitimate agents. Respondents felt that that the divide between communities and rangers could be partly attributed to the 'ignorance of community members of the rangers' (Kenneth) and their duties.

Through such interactions, rangers may 'also be [better] informed' about the concerns and issues from the community's viewpoint (Ambrose), which further facilitates a community-driven, problem-solving policing model. For instance, respondents described the need to understand cultural values better, including 'taboos' (Wilson) and 'totems' (Gaetano), associated with different groups that live near protected areas. By expanding a Park's value beyond its monetary worth, respondents believed that it would be possible to develop context-specific and culturally-sensitive non-law enforcement strategies. Finally, study participants reflected on the importance of positively engaging with and obtaining acceptance from local community leaders.

\section{Providing tangible and sustainable alternatives to poaching}

Respondents described the need for tangible alternatives to poaching, which need to be sustainable and require direct input from the local community. They also expressed frustration with external agencies and organizations offering quick fixes with little consideration for long-term impacts. Although external support was welcomed, respondents believed that success ultimately rests in local solutions.

One suggested strategy was to employ community members in Park organizations. Although some respondents were hesitant about this approach because of the potential for corruption, others considered it to be a useful strategy because staff originating from nearby communities may be able to develop genuine community trust more easily. In addition to establishing a sense of ownership and stewardship of protected areas, respondents also believed that by providing alternatives, including employment opportunities, poaching could be reduced.

Rangers' perceptions of the effectiveness and challenges of different law enforcement strategies

We asked for rangers' opinions on the effectiveness of traditional strategies in reducing illegal activities in protected areas, and whether they believed that the criminal justice system is effective in deterring offenders (Table 2). Although most respondents viewed law enforcement strategies to be effective in reducing illegal activities, they considered the criminal justice system to be largely ineffective in deterring potential offenders. These findings appear paradoxical, but upon further inquiry we found that most respondents felt that it was other aspects of the criminal justice system, rather than the rangers' work, that were problematic, including 'weak laws' (Charles) and the fact that the 'courts are corrupt' (Joshua). Despite the perceived deterrent value of traditional law enforcement strategies, respondents pointed to several limiting factors, such as the inability to monitor the protected areas adequately because of their size, access difficulties and restricted availability of resources; or as one respondent put it: 'Rangers can't be with every elephant' (Emmanuel).

When asked about the effectiveness of alternative, nonlaw enforcement approaches to safeguard protected areas, participants viewed such activities to be largely effective (Table 2). Although their operational mandate centred on monitoring within protected areas, law enforcement rangers 
TABLE 2 Study participants $(n=89)$ compared the effectiveness of traditional law enforcement strategies and the criminal justice system, and alternative approaches in safeguarding protected areas in Uganda.

No. of respondents

with supporting

Statements

statements

Supporting quotes

\section{Traditional law enforcement strategies \& the criminal justice system ..}

are effective in safeguarding protected 53

areas

are ineffective in safeguarding protected

areas

can be effective, but require other

strategies or community

support as well

Respondents did not provide an opinion $\quad 16$ Alternative, non-law enforcement strategies ... are effective in safeguarding protected areas 61

are ineffective in safeguarding protected

areas

can be effective, but require traditional law

enforcement as well

Respondents did not provide an opinion
They are effective. 'Cause if you arrest the same people who are poaching over \& over again. They will have fear. They will not return to the forests. (Ezra)

They are effective because, eh, mostly when our presence in that area scare away those people who are engaged in entering the Park for illegal activities [...] Because any time they can be arrested. (Robert) Law enforcement? They are not effective. Patrols are not effective in reducing poaching. (Roger)

Patrols? They are not effective [...] Patrol cannot help except make us aware of the enemies' changes in their [poaching] activities. But they (patrols) cannot effectively wipe out poaching. (Mugisa)

The patrols are very effective in reducing poaching, because you find that law enforcement has done very great work in removing some guns from the communities, arresting notorious poachers, those who poach with weapons \& spears. But on the other hand, law enforcement cannot be effective in reducing poaching by itself. It needs a combined effort from different departments, tourism \& community conservation. (Bernard)

Law enforcement alone cannot be effective. They have to work hand in hand [with Community Conservation Department]. Law enforcement patrols should work hand in hand with the sensitization of the community. But if only patrols? Poaching cannot even reduce. (Marvin)

$\mathrm{n} / \mathrm{a}$

I think tools of knowledge in somebody's brain is better [than patrols] [...] I think the sensitization is more effective [...] When the animal, for instance, has already been killed. When you meet with him (poacher), he is carrying that game meat but whereas if that person was sensitized before entering the Park, then maybe he would know the benefits of conservation \& he doesn't go in there to kill the animal. (Boaz)

Yeah, it would help because when they go \& they educate the local communities about the dangers of poaching \& how they are benefitting from the Protected Area. (Josephine)

Because the poachers, for them, even if you sensitize them, there are those who don't care. They just hear, but they can't put down [their weapons]. That word (the message) is in their mind, but it can't affect what you are telling them. So, you find they are continuing doing what they want. (Nicolas)

People who have reputations of poaching mostly don't attend the meetings. You find that community meetings are always attended by those who don't even have intentions of entering the Park for anything. They are the ones at the meeting. Poachers are not there [...] They (poachers) fear maybe they can be pin-pointed (identified) in the meeting that they are poachers, so most of them don't attend those meetings. That's why community conservation meetings are not effective. (Robert)

Need both. [We] can't rely on meetings. Some [community members] are double agents. (Gloria)

We should base on sensitization, \& then, you know, we enforce the law. (Christian)

$\mathrm{n} / \mathrm{a}$ 
Table 2 (Cont.)

\begin{tabular}{|c|c|c|}
\hline Statements & $\begin{array}{l}\text { No. of respondents } \\
\text { with supporting } \\
\text { statements }\end{array}$ & Supporting quotes \\
\hline \multicolumn{3}{|c|}{ Which is more effective in protecting protected areas: patrols or community meetings? } \\
\hline Patrols & 14 & $\begin{array}{l}\text { The patrols are effective because they go inside the Park. Because the } \\
\text { patrols move. [Patrols] does a better work [than community meet- } \\
\text { ings]. Checks all over the place (Park). Yes, as I've told you, you go to } \\
\text { the community, you sensitize the community, out of ten (commu- } \\
\text { nity members), three will go \& poach. (Edgar) } \\
\text { Patrol is not only helping stop poaching, it even helps in collecting } \\
\text { other data to understand what is happening in the area. If there is a } \\
\text { break-out disease, how will we know? You have to do the patrol. } \\
\text { (Jacqueline) }\end{array}$ \\
\hline Community meetings & 21 & $\begin{array}{l}\text { Law enforcement patrols? You know, it's better to first know the } \\
\text { core issue of what? Poaching [...] Prevention is better. The treat- } \\
\text { ment is now that law enforcement, which goes \& does action (pa- } \\
\text { trol). But, me, I would [suggest] sensitizing the community fast. [It] } \\
\text { would be better than doing the operations by the law enforcement. } \\
\text { (Christian) } \\
\text { You see, something has to be done outside here to the communities } \\
\text { before we get into the Park. Why I'm coming up with that? Look at } \\
\text { the size of the population of the rangers \& of the community people } \\
\text { who are not cooperating with rangers. The other group is big. So, } \\
\text { they can still overpower us. As in terms of concealing information or } \\
\text { of shielding wrong-doers. So, I'm saying something has to be done } \\
\text { outside the Park first to change the general feeling of the local people } \\
\text { to the wild animals. Much money has to be put in sensitizing the } \\
\text { local communities. (James) } \\
\text { The [community] meetings are better. Prevention is better than the } \\
\text { cure. I know the moment they (poachers) get into the Park, it is not } \\
\text { easy to get them. Because somebody can poach more than four times } \\
\text { without [us] getting them, but when you get them outside [within] } \\
\text { the community, then they stay \& they keep out [of the Park] [...] } \\
\text { [Meetings] are better than making patrols inside. It will prevent. } \\
\text { Because at times we get poachers when they have already killed. That } \\
\text { would be another way of saving animals. (Jacob) }\end{array}$ \\
\hline Both are effective & 31 & $\begin{array}{l}\text { They are both effective. In the meetings, you sensitize them \& people } \\
\text { understand more if they get to know the benefits of the Park. It will } \\
\text { reduce poaching. Then on patrol, you get someone, who is then } \\
\text { penalized, \& it puts fear in them. (Ezra) } \\
\text { Both can work hand-in-hand. But I think until a person under- } \\
\text { stands being advised is more than community conservation is more } \\
\text { than law enforcement. But there are some people who don't } \\
\text { understand \& we (law enforcement) will get them. (Judith) } \\
\text { If we arrest, no matter how much, people don't change. That's why } \\
\text { community conservation rangers sensitize. If people don't adjust, } \\
\text { then law enforcement arrests. All departments are important. We } \\
\text { have one objective: conservation. (Alice) }\end{array}$ \\
\hline Respondents did not provide an opinion & 23 & $\mathrm{n} / \mathrm{a}$ \\
\hline
\end{tabular}

recognized that illegal activities stemmed from problems outside Park boundaries. Respondents understood that traditional law enforcement strategies fail to address underlying problems, such as poverty and population growth, which put increasing pressure on protected areas. Study participants also highlighted several challenges that limit the effectiveness of alternative, non-law enforcement strategies, including the bureaucratic nature of memorandums of understanding and the fact that it is difficult for community members to access Park headquarters and request support. Continued negative interactions with wildlife also led to sustained difficulties between rangers and community 
members. Communities were not compensated for losses, and damage caused by wildlife was viewed as particularly problematic for lower-income and impoverished communities living near protected areas.

The distribution of Park revenue was also identified as a potential problem. Specifically, interviewees reported that funds distributed at the district level could be considerably reduced by the time they reached individual villages. Some respondents attributed this to corruption amongst politicians who 'end up eating it (taking the funding) without giving it to the community' (Wilson). Respondents claimed the communities 'don't see directly' (Bosco) the proceeds or 'tangible benefits' (Bernard) from the Park.

Study participants also believed that community members still feared rangers or did not trust them. This was exacerbated when local leaders were not involved as mediators between the two parties. Furthermore, where access was difficult or community members were unwilling to participate, conservation meetings were poorly attended and ineffective.

To further assess the nuances between traditional law enforcement activities and alternative approaches, respondents were asked which was more effective at reducing poaching within protected areas: patrols or community meetings. Respondents who believed that patrols were more effective than community meetings attributed this to the deterrent nature of such patrols, and that regardless of community meetings, there would always be individuals engaged in illegal activities. Study participants further explained that patrols provide vital information for protected area management (i.e. wildlife population counts) and thus are effective beyond their anti-poaching function.

Conversely, rangers who believed that community meetings were more effective than patrols proposed that meetings not only educated citizens on the Park's benefits, but also fostered lines of communication. Respondents also referenced the limitations associated with the reactionary nature of patrol activities and stated that apprehending suspects only after they had poached was still problematic. Although arrests can be viewed as a measure of success from a legal and tactical standpoint, the fact that a poaching incident still occurred was considered a failure from a conservation standpoint.

Taking into account the complexity of issues within and beyond Park boundaries, several interviewees considered both patrols and community meetings necessary to address wildlife crime. From this perspective, respondents pointed to the complementary nature of these strategies and highlighted how each approach can be helpful in addressing specific communities and individuals.

\section{Rangers' training and capacity development}

Of the 51 study participants who explicitly mentioned the need for additional training, 36 highlighted the need for 'capacity-building programmes that are not based on military skills' (Joshua), including training in ecology, community-based conservation, human rights, law enforcement and policing, technology, and criminal intelligence. Although respondents recognized the importance of military training for their operations, they also expressed their desire for professional development that broadened their capabilities. It was believed that such training could 'transform rangers [including their] attitude and reasoning' (James). Numerous interviewees $(n=44)$ also commented on the need for law enforcement rangers to be explicitly trained in community-oriented conservation approaches.

Respondents $(n=31)$ commented on the potentially detrimental nature of viewing community sensitization solely within the purview of the Community Conservation Department and neglecting the role of law enforcement in fostering community relations. In his response, Bosco mentioned, 'Rangers need more training on how to handle communities. And then rangers can realize that they can do nothing without communities in conservation' and Marvin added, 'They [rangers] also need to be trained in human resources and human rights.'

\section{Discussion}

Our findings suggest that rangers are more than enforcers of protected area laws and regulations and are willing to engage in activities associated with a community-oriented, problem-solving policing model. This receptivity to alternative, non-enforcement strategies bodes well for ranger capacity-building and complements the community-based natural resource management approach discussed by Challender \& MacMillan (2014). Such perspectives are encouraging because they illustrate rangers are willing to move beyond their current responsibilities and broaden the scope of their activities. Our study supports the push towards a more community-focused, problem-solving policing approach in a conservation context and emphasizes the view that rangers are vested stakeholders, rather than passive staff.

In addition, our research points to the need for a paradigm shift from wildlife law enforcement to wildlife policing in Uganda, to properly account for the breadth of rangers' responsibilities. Viewing rangers as a policing body broadens the scope of front-line personnel to account for and entrench non-enforcement activities. Although law enforcement and policing are often viewed as synonymous, they are not the same. Policing encompasses a wide range of activities and is largely viewed as a social service. Wildlife law enforcement should be viewed the same way. A focus on policing rather than anti-poaching facilitates the opportunity to reassess current training procedures, emphasizing broad-scope police training rather than relying primarily on 
paramilitary training. The potential for supplementary policing training based on a community-oriented, problem-solving model, and one that also includes courses on human rights and ecology, appears to be welcomed by the individuals who would receive such capacity building opportunities.

The shift towards wildlife policing from a more militarized law enforcement model should not be symbolic. Prior attempts to shift away from a 'coercive military culture' have highlighted the complexity of such change and the necessity for 'fundamental changes in the recruitment and training of park staff and the gradual building of a new set of norms [...] from the highest levels of management to the lowest' (Infield \& Namara, 2001, p. 58). Considerable investment must be placed on evaluating the organizational structure, the occupational culture of management and rank-and-file, and the broader immediate social ecology. Policing does not operate within a vacuum, and neither does wildlife law enforcement. Management should be adaptive and rangers must be attentive to the needs and concerns of the communities they serve, as well as recognizing the need for appropriate and procedurally just interactions with the community within and outside protected areas. Although their involvement is important, local governments have so far played a limited role in protected area management in Uganda (see Blomley et al., 2010). This is a missed opportunity; prior policing research has found that engaging local leaders is important in improving police legitimacy and cultivates informal social control.

The expanded use of strategies beyond the criminal justice system is a fundamental aspect of problem-oriented policing and encourages the use of alternative approaches before resorting to traditional law enforcement activities. Although agencies responsible for the management and monitoring of protected areas are still likely to operate from a paramilitary structure in some areas, a bottom-up rather than a traditional top-down flow of information is required. This ensures that community concerns and problems are articulated and contextualized by rangers who are most familiar with such issues, resulting in the development of tailored responses that may be more effective than generic reactions. Front-line rangers also need information on the effectiveness of specific strategies. Such reciprocity of information is key in establishing personnel acceptance and minimizing resistance.

Our study is not without limitations. The case study nature of this research limits the transferability of findings to other settings, including within Uganda. Furthermore, the credibility of our findings could be questioned, given potential for data inaccuracy or misinterpretation (Lincoln \& Guba, 1985). To minimize such problems, most interviews were digitally recorded to ensure data fidelity (Lincoln \& Guba, 1985). Additionally, data from interviews, narratives and observational field notes were triangulated to provide an inclusive representation of respondents' experiences. WDM also performed member checks (Lincoln \& Guba, 1985) with study participants to ensure that early interpretations of the data were accurate and contextually appropriate. Finally, although our findings cannot readily be applied to other settings, they are 'generalizable to theoretical propositions' (Yin, 2009, p. 15), particularly within the science of policing and the human dimensions of conservation.

Future studies should assess whether our findings in Uganda extend to protected areas in other countries. Scholars should also investigate whether rangers operating in different forms of protected area management (i.e. statesponsored compared to private game reserves) or rangers operating within one organization but in different departments hold similar opinions regarding a communityoriented, problem-solving policing model. Survey research based on a larger number of rangers could facilitate statistical examination of such group comparisons. Additionally, research is required regarding whether policy makers hold positive attitudes towards the strategies discussed in this study.

Our research suggests that a move towards a protected area model of management and monitoring that emphasizes a community-oriented, problem-solving framework could be a welcomed strategy, compared to one based on a militarized, deterrence-based approach. However, direct insight and involvement from those responsible for the monitoring of protected areas is required to make such transformation a reality. The belief that rangers are responsible only for activities that occur within protected areas must be overturned because such perspectives diminish the influence of rangers and neglect their role as key agents for change in conservation.

Acknowledgements The authors thank the study participants who shared their experiences and viewpoints, and the Editor and anonymous reviewers for their critiques and suggestions.

Author contributions Study concept and writing: WDM and RC; data collection and analysis: WDM.

\section{Conflicts of interest None.}

Ethical standards The study was approved by the University of Central Florida Institutional Review Board (SBE-14-10206) and the Uganda Council for Science and Technology (SS 3526). We obtained prior informed consent from all interview respondents. This research abided by the Oryx guidelines on ethical standards.

\section{References}

Auerbach, C. \& Silverstein, L.B. (2003) Qualitative Data: an Introduction to Coding and Analysis. NYU Press, New York, USA. Barichievy, C., Munro, L., Clinning, G., Whittington-Jones, B. \& Masterson, G. (2017) Do armed field-rangers deter rhino poachers? An empirical analysis. Biological Conservation, 209, 554-560.

BLOMLEY, T. (2003) Natural resource conflict management: the case of Bwindi Impenetrable and Mgahinga Gorilla National Parks, Southwestern Uganda. In Natural Resource Conflict Management 
Case Studies: an Analysis of Power, Participation and Protected Areas (eds P.A. Castro \& E. Nielsen), pp. 231-25o. Food and Agriculture Organization of the United Nations, Rome, Italy.

Blomley, T., Namara, A., McNeilage, A., Franks, P., Rainer, H., Donaldson, A. et al. (2010) Development AND Gorillas? Assessing Fifteen Years of Integrated Conservation and Development in South-Western Uganda. International Institute for Environment and Development, London, UK.

Challender, D.S. \& MacMillan, D.C. (2014) Poaching is more than an enforcement problem. Conservation Letters, 7, 484-494.

Dey, I. (1999) Grounding Grounded Theory. Academic Press, San Francisco, USA.

Gill, C., Weisburd, D., Telep, C.W., Vitter, Z. \& Bennett, T. (2014) Community-oriented policing to reduce crime, disorder, and fear and increase satisfaction and legitimacy among citizens: a systematic review. Journal of Experimental Criminology, 10, 399-428.

Goldstein, H. (2003) On further developing problem-oriented policing: the most critical need, the major impediments, and a proposal. In Problem-Oriented Policing: from Innovation to Mainstream, Crime Prevention Studies, Vol. 15 (ed. J. Knutsson), pp. 13-48. Criminal Justice Press, Monsey, USA.

Infield, M. \& Namara, A. (2001) Community attitudes and behaviour towards conservation: an assessment of a community conservation programme around Lake Mburo National Park, Uganda. Oryx, 35, 48-6o.

Kennedy, D.M. (2009) Deterrence and Crime Prevention: Reconsidering the Prospect of Sanction. Routledge, New York, USA.

LaWrence, S. \& McCarthy, B. (2013) What Works in Community Policing? The Chief Justice Earl Warren Institute on Law and Social Policy, Berkeley, USA.

Lincoln, Y.S. \& GubA, E.G. (1985) Naturalistic Inquiry. Sage Publications, Thousand Oaks, USA.
Moore, J.F., Mulindahabi, F., Masozera, M.K., Nichols, J.D., Hines, J.E., Turikunkiko, E. \& Oli, M.K. (2018) Are ranger patrols effective in reducing poaching-related threats within protected areas? Journal of Applied Ecology, 55, 99-107.

Moreto, W.D. (2019) Provoked poachers? Applying a situational precipitator framework to examine the nexus between human-wildlife conflict, retaliatory killings, and poaching. Criminal Justice Studies, 32, 63-80.

Moreto, W.D., Brunson, R.K. \& Braga, A.A. (2017) 'Anything we do, we have to include the communities': law enforcement rangers' attitudes towards and experiences of community-ranger relations in wildlife protected areas in Uganda. British Journal of Criminology, 57, 924-944.

Moreto, W.D., Gau, J.M., Paoline, E.A., Singh, R., Belecky, M. \& LONG, B. (2017) Occupational motivation and intergenerational linkages of rangers in Asia. Oryx, published online 22 August 2017.

National Research Council (2004) Fairness and Effectiveness in Policing: the Evidence (eds W. Skogan \& K. Frydl). The National Academies Press, Washington, DC, USA.

Patton, M.Q. (2015) Qualitative Research \& Evaluation Methods: Integrating Theory and Practice. 4th edition. Sage Publications, Thousand Oaks, USA.

SAldañA, J. (2016) The Coding Manual for Qualitative Researchers. 3rd edition. Sage Publications, Thousand Oaks, USA.

Tindifa, S.B. \& Kiguli, J. (1997) Community Policing Report. The Department of International Development, Nairobi, Kenya.

VAn der Spuy, E. \& Röntsch, R. (2008) Police and Crime Prevention in Africa: a Brief Appraisal of Structures, Policies and Practices. International Centre for the Prevention of Crime, Cape Town, South Africa.

YIN, R.K. (2009) Case Study Research: Design and Methods. 4th edition. Sage Publications, Thousand Oaks, USA. 